\title{
CLEANING AND CARE OF THE NATIONAL GALLERY PICTURES
}

\author{
By W. G. CONSTABLE
}

\author{
Curator of Paintings, Museum of Fine Arts, Boston, Mass.
}

$\mathrm{N}_{\text {has to }}^{\circ}$ OW that the dust of controversy over the cleaning of certain National Gallery pictures has to some extent settled, it is possible to judge some of its results. The ineptitude of much of the criticism should not blind us to its value. Apart from witnessing how greatly some of the owners of the pictures care about them, both the praise and blame meted out to the National Gallery authorities have revealed a fundamental confusion of thought over the cleaning of pictures-confusion between how a painting looks after treatment, and how its physical condition has been affected. Whether the spectator likes the appearance of a painting is a matter of taste, whereas its physical condition is a matter of fact; but only too often those who by habit or conviction like to see paintings as in a glass darkly make reckless charges of removal of original glazes, abrasion of surface and so on. That is not to say that criticism of appearance is unjustifiable. Pictures are meant to be looked at, and when all excrescences such as dirt, discoloured varnish and later repaints have been removed, a painting does not necessarily look as the artist meant it to look. Colours may have changed ; there may be breaks in the surface ; cracks may have developed; the pigment layer may have become more transparent with time, revealing the painter's earlier intentions or, in the case of paintings on a dark ground, causing the tone of whole areas to be lowered and so obscuring detail. It therefore becomes a problem for those in charge of paintings to decide what should be done in such cases; and the decision will range from merely 'in-painting' with a neutral colour the most obvious and disturbing breaks, to an elaborate tinting out of all blemishes and the use of a toned varnish, or retention of some of the old, to unify the whole. One thing is certain, however, we can never be quite sure how the painter intended his work to look; and since succeeding generations will have their own opinions on the matter, anything added to or left on a painting in the interests of appearance should be incapable of doing harm, and should be easily and safely removable.

This particular problem, however, was only raised by implication during the controversy; and both the National Gallery authorities and the Committee of Confidential Inquiry appointed by the Trustees have confined themselves to the question of the physical condition of the pictures, and how it has been affected by cleaning, both recently and in the past. The National Gallery presented its case in the form of the "Exhibition of Cleaned Pictures", which was reviewed in an article in Nature of October 18, 1947; and what follows is concerned only with the Report of the Committee. This consisted of Dr. P. Coremans, head of the Central Laboratory, Belgian National Museums; Dr. G. L. Stout, former head of the Department of Conservation, Fogg Museum of Art, Harvard University, now director of the Worcester Art Museum, Massachusetts; and Dr. J. R. H. Weaver, president of Trinity College, Oxford, who acted as chairman. It is difficult to imagine a committee technically better equipped, and more independent and judicially minded; and the report should become a locus classicus on certain aspects of cleaning. Presumably for reasons of economy, the report has not been published, but mimeographed copies may be consulted at the Victoria and Albert and the British Museums; an article on the report by Dr. Weaver appeared in The Times of May 8.

The report falls into two main parts. The first gives the results of intensive examination of ten recently cleaned pictures of diverse types, including all those the cleaning of which has been most severely criticized, notably Rembrandt's "Woman Bathing", Rubens' "Chapeau de Paille", and Velazquez's "Philip IV when elderly". The second part sum. marizes the results of this examination, and makes a series of recommendations on future practice and policy in cleaning, and on general measures for conservation. In the examination of the ten selected pictures, not only were all available records of cleaning taken into account, but also the criticisms and comments which have been made in the Press. The broad result cannot be more succinctly stated than in the words of the report. "In the ten pictures which were examined no damage was found to have resulted from the recent cleaning either because of a partial solution of original paint or because of abrasion or rubbing of original paint at the time when extraneous materials were removed from it." As regards particular pictures, of the Rembrandt it is said, "Adverse comments . . . centered on alleged damage, during recent cleaning, to the proper right wrist and hand. There is no evidence to support the view that such damage has occurred" ; the conclusion concerning the Rubens' "Chapeau de Paille" is that "the procedure in the cleaning of 1946 seems to have been sound; there is no evidence of loss at that time or of any substantial deposits of extraneous material left on the original paint"; while of the Velazquez it is said, "Losses in the paint are minor ones and all were present before the cleaning began in 1946. Part of the former surface coating still remains. There is no evidence of any damage from recent treatment."

All this is interesting enough in itself and most reassuring. But equally interesting are the methods by which the conclusions were reached. The Committee was presented with a new type of problem. Analysis of a painting to ascertain its present physical condition, by such means as X-ray, ultraviolet light, microscopic and chemical analyses, etc., is nowadays standard procedure; but to discover what, if anything, had been removed from a painting at different periods in its history meant adapting these methods of investigation to new uses, and inventing others. A procedure used in every case was to test the solubility of the original paint layer with various solvents. This varied according to whether a resin had been mixed with the oil medium; but in all cases the original paint layer resisted much stronger solvents than those recorded to have been used in the recent cleaning. Close examination of the structure of the paint layer also proved valuable. In the "Chapeau de Paille", for example, a greenish-blue paint visible in part of the sky was alleged by a critic to have once covered the blue of the sky as it now appears; but this greenish-blue is now proved to be below the blue, which was applied in places to modify it. To estimate whether a 
surface had been abraded, comparison with areas which could reasonably be regarded as in their original state was the standard test. X-ray photographs taken in the past were a means of judging whether paint that had been removed was original or a later re-paint, notably in the case of the Rembrandt; and ultra-violet light was extensively used to ascertain whether, in areas alleged to have been damaged, old varnish still remained. Occasionally, as confirmatory evidence, the material in swabs used in cleaning a painting was analysed. In one case, at least, zinc white was discovereda pigment unknown at the date of the painting, and so an indication that a later re-paint had been removed. Rightly, however, the report discounts the value of such evidence, owing to the difficultyoften impossibility - of distinguishing original pigment from that used later.

Though the report thus completely vindicates the National Gallery authorities on the main charges brought against them, it has also found occasion for some mild criticism. One ground for this, which may prove disconcerting to those who have assailed recent cleaning, is that some pictures, notably the Rubens' "Brazen Serpent", "Autumn : The Château de Steen", and "Peace and War", have not been cleaned enough, either in the interests of safety or of appearance. Old varnish or re-paints left on a picture are potential agents in disrupting the original surface, and if softened by partial cleaning may penetrate deeper into the interstices of the original paint, and so increase the difficulty of their removal, and their power to do harm; while their effect in throwing part of the painting out of tone may be considerable. In this connexion, the report brings out the difficulty of removing an old varmish or a re-paint, if the medium used by the artist contains a resin similar to that present in the extraneous elements, since the solvents used for removal may attack the original pigment layer. This danger was diagnosed by Faraday so long ago as 1853, and creates a difficulty in cleaning Constable's "Corn. field". In fact, in this picture and Rutens' "Rape of the Sabines", while noting the presence of extraneous and therefore possibly deleterious elements, the Committee holds that "special problems encountered in the process of cleaning would be considered to warrant accepting the present state as the best that could practically be reached".

Considerations of this kind lead to the more general conclusion that "materials used for cleaning ... can be considered safe or unsafe only with respect to a particular piece of paint", and that "it is not even certain that the same solvent . . . can be considered quite safe over the entire area of one picture. In any part of a picture, safety is relative to other factors, particularly to timing and manipulation." This emphasizes how important is full diagnosis before a painting is cleaned. X-ray, ultra-violet light, infra-red rays, the tintometer, analysis of pigment layer and varnish, experimental tests in unimportant areas, must all be made and their results checked against each other. No one man can be expected to apply all these means of investigation; and so the system of modern medical practice must be followed, of specialist reports being put at the service of the man in charge, the cleaner. He, too, should be the centre of another set of specialist researches concerned with the materials he uses. Much has been discovered about solvents and protective coating materials; but much remains to be done in selecting and adapting them for use on paintings. In the last resort, however, it is the wisdom and skill of the cleaner which count. The scientific investigator can give him the facts, but he has to interpret them, estimate their significance and act upon them. In incompetent hands, any materials can do harm to a painting, especially if camouflaged by a little scientific knowledge; and the ideal cleaner adds, to wisdom and skill, sensibility and integrity. It is easy to produce a result which will fool for a time anyone save an expert, but which has either damaged the painting or sown the seeds of future trouble. The cleaner's responsibilities, moreover, do not end with cleaning. The report emphasizes the necessity of full and precise record, not only of diagnosis but also of treatment, as an indispensable guide to possible future action; and in preparing such a record the cleaner must play a leading part.

Another criticism suggested is the need for greater attention to the supports of paintings. It is not always sufficiently realized that an oil painting consists of several layers: the support, usually canvas or panel; the ground; the pigment held in a medium; and the protective covering. Each of these layers is liable to expand, contract or dis. integrate on its own account, and thereby affect the appearance and condition of the painting; and imperfect bonding between the layers may intensify the trouble. Cleaning, in the ordinary sense of the term, is concerned with the protective coating and the pigment layer alone, in the interests of safety and of enabling the picture to be seen at what is thought to be its best. But properly considered, cleaning is only one part of the business of keeping every element of a painting in good health. Treat. ment of the supports of painting, however, requires more investigation and thought than it has hitherto received. It is not so long ago, for example, that glue was the universally accepted adhesive for attaching a new canvas on the back of an old one (the process known as 'lining'); while defective panels were always 'cradled', that is, secured on the back by a series of criss-cross slats. Both methods are now known to be at best unsatisfactory, and at worst dangerous; but though they are now falling into disrepute, no completely satisfactory sub. stitutes have yet been found. It is to be hoped, therefore, that any campaign to put the supports of National Gallery paintings in order will be tentative, and based upon experiment and research.

One step, however, can be taken at once which can only have the most salutary results, that of controlling temperature and humidity conditions in the National Gallery. Experience in the quarry at Manod, where the paintings were stored during the War, proved how beneficial such control can be ; while the disastrous effect of its absence is demon. strated by the cracking and warping of the panel on which Rubens' "Autumn : The Château de Steen" is painted, during the hard frost of January 1947. Let no one think, however, that air-conditioning is a complete answer to the problem of keeping pictures in good health. In a public gallery, the public themselves introduce variable elements of heat and humidity, which so far no system has been able to control. But it will not be the least of the services of the Committee of Inquiry to the public, if its recommendation that full air-conditioning be installed in the National Gallery is accepted and speedily implemented by those responsible. 